\title{
Blockade of NK-1 receptors in the lateral commissural nucleus tractus solitarii of awake rats had no effect on the cardiovascular responses to chemoreflex activation
}

L.G.H. Bonagamba and B.H. Machado
Departamento de Fisiologia, Faculdade de Medicina de Ribeirão Preto, Universidade de São Paulo, Ribeirão Preto, SP, Brasil

\section{Correspondence \\ B.H. Machado \\ Departamento de Fisiologia \\ FM RP, USP \\ Av. Bandeirantes, 3900 \\ 14049-900 Ribeirão Preto, SP \\ Brasil \\ Fax: + 55-16-633-0017 \\ E-mail: bhmachad@fmrp.usp.br \\ Research supported by FAPESP, CNPq and PRO NEX. C. Zhang was the recipient of a CNPq postdoctoral fellowship (No. 150065/96-5)}

Received January 21, 2000 Accepted August 7, 2000

\section{Abstract}

The neurotransmission of the chemoreflex in the nucleus tractus solitarii (NTS), particularly of the sympatho-excitatory component, is not completely understood. There is evidence that substance P may play a role in the neurotransmission of the chemoreflex in the NTS. Microinjection of substance $\mathrm{P}(50 \mathrm{pmol} / 50 \mathrm{nl}, \mathrm{N}=12$, and $5 \mathrm{nmol} / 50$ $\mathrm{nl}, \mathrm{N}=8$ ) into the commissural NTS of unanesthetized rats produced a significant increase in mean arterial pressure $(101 \pm 1$ vs $108 \pm 2$ and $107 \pm 3$ vs $115 \pm 4 \mathrm{mmHg}$, respectively) and no significant changes in heart rate $(328 \pm 11$ vs $347 \pm 15$ and $332 \pm 7$ vs $349 \pm 13$ bpm, respectively) $2 \mathrm{~min}$ after microinjection. Previous treatment with WIN, an NK-1 receptor antagonist $(2.5 \mathrm{nmol} / 50 \mathrm{nl})$, microinjected into the NTS of a specific group of rats, blocked the pressor $(11 \pm 5 \mathrm{vs}$ $1 \pm 2 \mathrm{mmHg}$ ) and tachycardic ( $31 \pm 6 v s 4 \pm 3 \mathrm{bpm})$ responses to substance $\mathrm{P}(50 \mathrm{pmol} / 50 \mathrm{nl}, \mathrm{N}=5)$ observed $10 \mathrm{~min}$ after microinjection. Bilateral microinjection of WIN into the lateral commissural NTS $(\mathrm{N}=8)$ had no significant effect on the pressor $(50 \pm 4 v s 42 \pm 6$ $\mathrm{mmHg})$ or bradycardic $(-230 \pm 16 v s-220 \pm 36 \mathrm{bpm})$ responses to chemoreflex activation with potassium cyanide $(i v)$. These data indicate that the activation of NK-1 receptors by substance P in the NTS produces an increase in baseline mean arterial pressure and heart rate. However, the data obtained with WIN suggest that substance P and NK-1 receptors do not play a major role in the neurotransmission of the chemoreflex in the lateral commissural NTS.

\section{Introduction}

Studies from our laboratory have evaluated the autonomic processing of the cardiovascular reflexes in the nucleus tractus solitarii (NTS), with particular emphasis on the role of excitatory amino acid (EAA) receptors (1-6). Several studies have indicated a

\section{Key words}

- Tachykinins

- Cardiovascular regulation

- Carotid chemoreceptors

- Autonomic regulation

- NK-1 receptors

- Substance P 
chemoreflex in the NTS (11-14).

In a recent study (15) we observed that microinjection of EAA receptor antagonists (kynurenic acid; 6,7-dinitroquinoxaline-2,3dione (DNQX) or $\alpha$-methyl-4-carboxyphenylglycine (MCPG)) into the NTS produced only partial blockade of the pressor response to chemoreflex activation, indicating that the sympatho-excitatory component of this reflex was not exclusively mediated by Lglutamate and EAA receptors. Considering the possible involvement of substance $P$ in the processing of the sympatho-excitatory component of the chemoreflex in the NTS (11-14), in the present study we evaluated the role of substance $\mathrm{P}$ and NK-1 receptors in the processing of the chemoreflex afferents in the lateral commissural NTS of awake rats. To achieve these goals we microinjected substance P into the NTS of awake rats before and after local microinjection of WIN, an NK-1 receptor antagonist, and we also activated the chemoreflex before and after bilateral microinjection of an effective dose of WIN into the lateral commissural NTS of awake rats. A preliminary report of these data has been published as an abstract (16).

\section{Material and Methods}

Male Wistar rats weighing 280-300 g were used in the present study. Four days before the experiments rats under $2.5 \%$ tribromoethanol anesthesia $(1 \mathrm{ml} / 100 \mathrm{~g}$, ip $)$ were placed in a stereotaxic apparatus (David Kopf, Tujunga, CA, USA) and the technique described by Michelini and Bonagamba (17) was used to implant bilateral guide cannulas in the direction of the lateral commissural NTS $(0.5 \mathrm{~mm}$ lateral to the midline and $\sim 0.5 \mathrm{~mm}$ rostral to the calamus scriptorium) according to the coordinates of the Paxinos and Watson atlas (18). To implant each guide cannula we made a small window in the skull caudal to the lambda and introduced a 15 -mm long stainless steel guide cannula (22 gauge; Small Parts, Miami Lakes, FL, USA) perpendicularly through the window at the following coordinates: $0.5 \mathrm{~mm}$ lateral to the bregma, $14.00 \mathrm{~mm}$ caudal to the bregma and $7.9 \mathrm{~mm}$ below the skull surface at the bregma. The tip of the guide cannula was positioned $\sim 1.0 \mathrm{~mm}$ above the dorsal surface of the brainstem. The guide cannula was fixed to the skull with methacrylate and watch screws and then closed with an occluder until the time of experimentation $(2,5,17)$. The needle (33 gauge, Small Parts) used for microinjection into the NTS was 1.5 $\mathrm{mm}$ longer than the guide cannula and was connected by PE-10 tubing to a $1-\mu 1$ syringe (Hamilton, Reno, NV, USA). The needles for microinjection of L-glutamate, used for functional identification of the NTS (5), substance $\mathrm{P}$ and WIN were carefully inserted into the guide cannula and manual injection was initiated $30 \mathrm{~s}$ later.

One day before the experiments, under $2.5 \%$ tribromoethanol anesthesia, a catheter (PE-10 connected to PE-50; Clay Adams, Parsippany, NJ, USA) was inserted into the abdominal aorta through the femoral artery for measurement of pulsatile arterial pressure (PAP), mean arterial pressure (MAP) and heart rate (HR). A second catheter was inserted into the femoral vein for drug administration. Both catheters were tunneled and exteriorized through the back of the neck to be connected to a pressure transducer under conscious freely moving conditions. PAP was measured with a pressure transducer (model CDX III; Cobe Laboratories, Lakewood, CO, USA) connected to a physiological recorder (Narcotrace 80; Narco Bio-Systems, Austin, TX, USA) and MAP was also evaluated using a Narco Universal gain coupler (type 7189). HR was quantified with a Narco biotachometer coupler (type 7302).

The chemoreflex was activated with potassium cyanide $(\mathrm{KCN}, 40 \mu \mathrm{g} / \mathrm{rat}, i v)$ according to the method described by Franchini and Krieger (19) and the cardiovascular responses to chemoreflex activation were evaluated before and 2, 10, 20 and $30 \mathrm{~min}$ 
after bilateral microinjection of WIN (2.5 $\mathrm{nmol} / 50 \mathrm{nl}$ ) into the lateral commissural NTS. At the end of each experiment $50 \mathrm{nl}$ of Evan's blue (2\%) was microinjected into the same sites for histological analysis. The animals were then submitted to intracardiac perfusion with saline followed by $10 \%$ buffered formalin under ether anesthesia. The brains were removed and stored in buffered formalin for 2 days, and serial coronal sections $(15 \mu \mathrm{m})$ were cut and stained by the Nissl method. Only the rats in which the site of microinjection was located in the lateral commissural NTS were used for data analysis.

The following drugs and solutions were used: saline $(0.9 \% \mathrm{NaCl})$, L-glutamate (Sigma Chemical Co., St. Louis, MO, USA), tribromoethanol (Aldrich Chemical Company, Inc., Milwaukee, WI, USA), KCN (Sigma), substance P (RBI, Natick, MA, USA) and WIN 51.708 (NK-1 receptor antagonist, RBI).

All values are reported as means \pm SEM. Statistical analysis was performed using oneway ANOVA and the paired Student $t$-test. Differences were considered significant at the $\mathrm{P}<0.05$ level.

\section{Results}

Changes in baseline MAP and $H R$ in response to bilateral microinjection of substance $P$ into the NTS

Table 1 shows the basal values of MAP and HR before and $2 \mathrm{~min}$ after bilateral microinjection of two doses of substance $\mathrm{P}$ (50 pmol/50 $\mathrm{nl}$ and $5 \mathrm{nmol} / 50 \mathrm{nl}$ ) or saline into the NTS of three different groups of rats. There were significant increases in basal MAP 2 min after microinjection of $50 \mathrm{pmol} /$ $50 \mathrm{nl}$ and $5 \mathrm{nmol} / 50 \mathrm{nl}$ of substance P compared to control. Considering that these two doses of substance $\mathrm{P}$ produced a similar increase in MAP, it is possible that both are in the maximal dose range and for this reason we used the dose of $50 \mathrm{pmol} / 50 \mathrm{nl}$ in the subsequent experiments.
Comparison of the changes in MAP and $\mathrm{HR}$ in response to two sequential bilateral microinjections of substance $\mathrm{P}(50 \mathrm{pmol} / 50$ $\mathrm{nl}$ ) into the NTS at 20-min intervals in a specific control group $(\mathrm{N}=5)$ showed no significant changes in the pressor $(9 \pm 3 v s 6$ $\pm 2 \mathrm{mmHg})$ or tachycardic responses $(32 \pm$ 12 vs $13 \pm 9 \mathrm{bpm})$ to substance P microinjection. These data show that repeated microinjections of substance P into the NTS produced no tachyphylactic effect.

\section{Effect of microinjection of WIN on the cardiovascular responses to microinjection of substance $P$ into the NTS}

Figure 1 summarizes the changes in MAP and $\mathrm{HR}$ at 2, 5 and $10 \mathrm{~min}$ after unilateral

Table 1 - Basal mean arterial pressure (MAP) and heart rate (HR) before and 2 min after bilateral microinjection of substance $\mathrm{P}(50 \mathrm{pmol} / 50 \mathrm{nl}$ and $5.0 \mathrm{nmol} / 50 \mathrm{nl})$ or saline into the NTS of three different groups of rats.

Values are reported as means $\pm \mathrm{SEM} . * \mathrm{P}<0.05$ compared to control (paired t-test).

\begin{tabular}{lrrrrrr}
\hline Substance $P$ & $N$ & \multicolumn{2}{c}{ MAP $(\mathrm{mmHg})$} & & \multicolumn{2}{c}{ HR (bpm) } \\
\cline { 3 - 4 } \cline { 7 - 7 } & & Before & After & & Before & After \\
\hline $50 \mathrm{pmol} / 50 \mathrm{nl}$ & 12 & $101 \pm 1$ & $108 \pm 2^{*}$ & & $328 \pm 11$ & $347 \pm 15$ \\
$5 \mathrm{nmol} / 50 \mathrm{nl}$ & 8 & $107 \pm 3$ & $115 \pm 4^{*}$ & & $332 \pm 7$ & $349 \pm 13$ \\
Saline & 4 & $103 \pm 1$ & $106 \pm 2$ & & $314 \pm 10$ & $313 \pm 9$
\end{tabular}

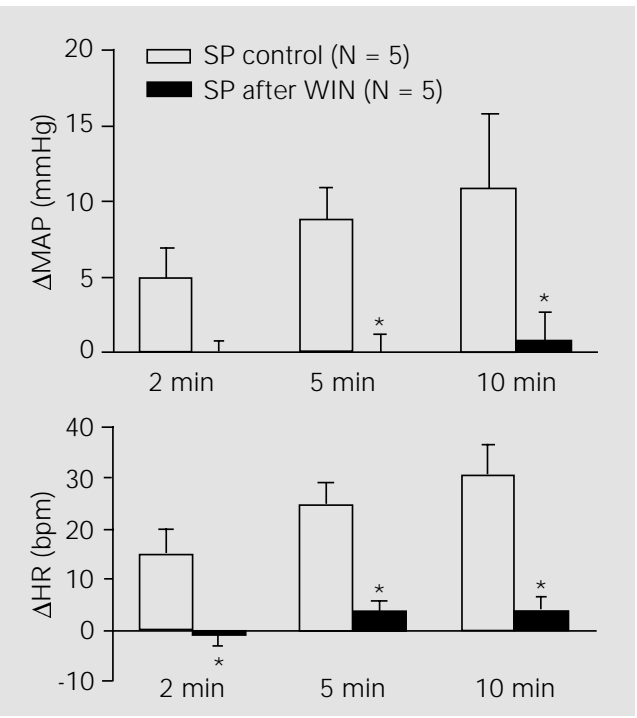

Figure 1 - Changes in mean arterial pressure $(\triangle \mathrm{MAP})$ and heart rate $(\triangle \mathrm{HR}) 2,5$ and $10 \mathrm{~min}$ after a control microinjection of substance $\mathrm{P}$ (SP, $50 \mathrm{pmol} / 50 \mathrm{nl}$ ) into the NTS and 2, 5 and 10 min after microinjection of substance $P$ preceded by microinjection of WIN $(2.5 \mathrm{nmol} / 50 \mathrm{nl})$ into the NTS. $* \mathrm{P}<0.05 \mathrm{com}$ pared to control (one-way ANOVA). 

conscious rat representative of the group showing the changes in heart rate (HR), pulsatile arterial pressure (PAP) and mean arterial pressure (MAP) in response to chemoreflex activation with potassium cyanide (KCN, $40 \mu \mathrm{g} / \mathrm{rat}$, iv) before and 2 , 10,20 and $30 \mathrm{~min}$ after bilateral microinjection of WIN $(2.5 \mathrm{nmol} /$ $50 \mathrm{nl}$ ) into the commissural NTS.

Figure 3 - Changes in mean arterial pressure $(\triangle M A P)$ and heart rate $(\triangle \mathrm{HR})$ in response to chemoreflex activation (KCN, $40 \mu \mathrm{g} /$ rat, iv) before (control) and 2, 10, 20 and 30 min after bilateral microinjection of WIN $(2.5 \mathrm{nmol} / 50$ $\mathrm{nl}$ ) into the NTS.
Figure 2 - Typical tracing of a

microinjection of substance $\mathrm{P}$ (50 pmol/50 $\mathrm{nl}$ ) into the NTS (control) and the changes in MAP and HR 2, 5 and 10 min after microinjection of substance $P$ following microinjection of WIN $(2.5 \mathrm{nmol} / 50 \mathrm{nl})$ into the same site. These data indicate that $2.5 \mathrm{nmol} / 50 \mathrm{nl}$ WIN produced a significant blockade of the increase in MAP and HR produced by mi-
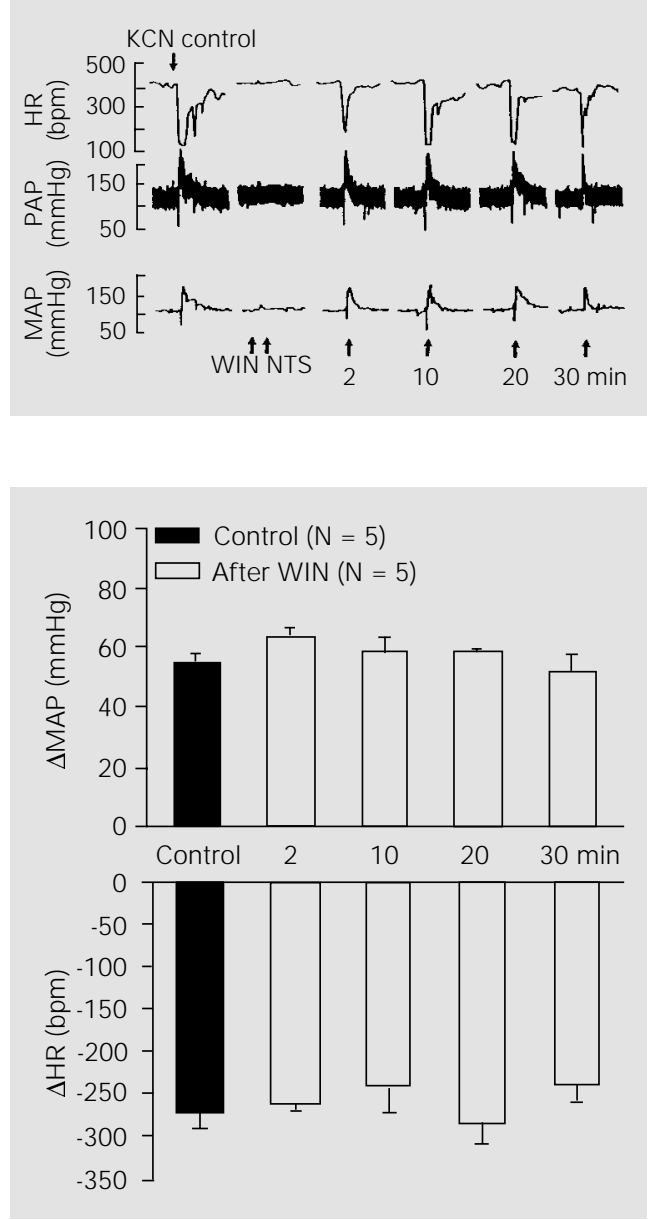

Figure 4 - Photomicrograph of a coronal section of the brainstem of one rat representative of the group that received bilateral microinjection of WIN showing the bilateral sites of microinjections in the lateral commissural NTS (Nissl, 120X). croinjection of substance P into the NTS at 2,5 and $10 \mathrm{~min}$. In a specific group of rats $(\mathrm{N}$ $=5)$ microinjection of a low dose of WIN (1 $\mathrm{nmol} / 50 \mathrm{nl}$ ) into the NTS produced no blockade in the cardiovascular responses to substance $\mathrm{P}$ (50 pmol/50 nl; data not shown).

\section{Effect of bilateral microinjection of WIN into the NTS on the chemoreflex}

Figure 2 presents a typical tracing of one rat representative of the group showing that the effect of bilateral microinjection of WIN $(2.5 \mathrm{nmol} / 50 \mathrm{nl})$ into the lateral NTS produced no changes in the cardiovascular responses to chemoreflex activation. The data summarized in Figure 3 show no significant changes in the pressor or bradycardic responses to chemoreflex activation at 2,10 , 20 and 30 min after microinjection of WIN when compared to control responses.

Figure 4 is a photomicrograph of a coronal section of the brainstem of one rat representative of the group that received microinjection of WIN and shows the bilateral sites of microinjection in the lateral aspect of the commissural NTS.

\section{Discussion}

The NTS is the site of termination of arterial baroreceptors, carotid chemoreceptors (chemoreflex) and cardiopulmonary afferents (Bezold-Jarisch reflex) in the brainstem and different subpopulations of postsynaptic neurons in the NTS are involved in the autonomic responses to the activation of these cardiovascular reflexes. In a recent study from our laboratory (15), we observed that microinjection of ionotropic receptor antagonists (kynurenic acid and DNQX) or a metabotropic receptor antagonist (MCPG) into the lateral commissural and medial NTS produced only partial blockade of the pressor response to chemoreflex activation, suggesting that the sympatho-excitatory component of this reflex is not exclusively medi- 
ated by EAA receptors (ionotropic and metabotropic). In view of these previous data and of evidence in the literature in favor of substance $P$ as a neurotransmitter of the chemoreflex $(13,14)$, in the present study we considered the possibility that substance $\mathrm{P}$ may be involved in the processing of the chemoreflex in the NTS, particularly in terms of the sympatho-excitatory component. For this reason we studied the possible role of substance $P$ receptors (NK-1) in the NTS in the processing of the chemoreflex in unanesthetized rats.

Substance $\mathrm{P}$ is a peptide belonging to the neurokinin family (20) and seems to play an important role as a neurotransmitter or neuromodulator in primary baroreceptor and chemoreceptor afferent fibers, but the mechanisms of action of substance $P$ in the brain with respect to the cardiovascular reflexes in the NTS are not completely understood (12,21-25). It is important to note that microinjections of substance P into the NTS have produced variable effects on arterial pressure in different studies. Whereas some investigators failed to elicit cardiovascular responses to microinjection of substance $P$ into the NTS $(26,27)$, others reported that substance $\mathrm{P}$ induced hypotensive responses $(22,23,25)$. The present study shows that bilateral microinjections of substance $P$ into the lateral commissural NTS of unanesthetized rats produced a significant long-lasting increase (at least $10 \mathrm{~min}$ ) in MAP and HR. On the other hand, the hypothesis that substance $\mathrm{P}$ may be involved in baroreflex neurotransmission was raised in studies showing that low doses of substance $\mathrm{P}$ into the NTS elicit decreases in arterial pressure $(11,25)$. However, at higher doses substance $\mathrm{P}$ produces long-lasting hypertension (24). The different cardiovascular responses to microinjection of substance P into the NTS may be related to the different experimental conditions used in each laboratory such as the anesthetic administered and the level of anesthesia. In the present study, we used unanesthetized rats because in a previous study we observed that urethane or chloralose anesthesia produced a major effect on the cardiovascular responses to microinjection of L-glutamate into the NTS (5).

In the present study, WIN, a selective, high-affinity, nonpeptide antagonist of NK1 receptors, was used to test the hypothesis that substance $\mathrm{P}$ acting on these receptors could be playing a role in the neurotransmission of the chemoreflex in the NTS. The effective dose of WIN to block NK-1 receptors was determined in experiments in which the long-lasting increase in MAP and HR produced by substance $\mathrm{P}$ was blocked by prior local administration of WIN. In these experiments we observed that substance $\mathrm{P}$ microinjected into the NTS produced significant cardiovascular changes which were entirely blocked by an NK-1 receptor antagonist. These data confirm findings of previous studies showing that substance $P$ and NK-1 receptors may play some role in cardiovascular regulation at the NTS level $(11,25)$.

The microinjection of an NK-1 receptor antagonist into the NTS produced no changes in the cardiovascular responses to chemoreflex activation at 2, 10, 20 and $30 \mathrm{~min}$ after bilateral microinjection, suggesting that substance $\mathrm{P}$ and particularly NK-1 receptors play no major role in the neurotransmission of the chemoreflex in the NTS. However, other studies $(14,21)$ have suggested a role for substance $P$ in the neurotransmission of the chemoreflex. Intracisternal injections of substance $\mathrm{P}$, for example, mimic the effects of hypoxia in normal rabbits while cats and rabbits submitted to hypoxic challenges showed an increase in substance $P$ release within some specific respiratory areas of the NTS. In addition, the increase in substance $P$ release was abolished in rabbits by bilateral carotid sinus nerve denervation (28). The contrasting data of the present study may be related to the different species used in other studies as well as to the fact that our experi- 
ments were performed in awake rats. Anesthetics significantly reduce the cardiovascular responses to the chemoreflex and consequently the neurotransmission at the NTS level may not be the same under anesthesia (19; Haibara AS and Machado BH, unpublished data).

Bilateral microinjection of an NK-1 receptor antagonist into the lateral commissural NTS, as shown in Figure 2, produced no changes in baseline MAP or HR, indicating that these receptors do not play a tonic role in the processing of the baroreflex at the NTS level. However, whether or not NK-1 receptors in the NTS play a neuromodulatory role in the gain of the baroreflex is still matter for further investigation in awake rats.

Substance $\mathrm{P}$ has also been suggested to be one of the major neurotransmitters of the primary afferent barosensory fibers that terminate in the NTS $(12,24)$. The study by Morilak et al. (24) using in vivo microdialysis showed that substance $P$ can be released in the medial intermediate NTS during bilateral stimulation of the aortic depressor nerve in the rabbit, but Feldman (29) reported that blockade of NK-1 receptors in the NTS has no effect on the baroreflex in urethane-anesthetized rats. There is also evidence showing that endogenous neurokinins, especially substance $\mathrm{P}$, act as mediators of stress responses in the brain (30). Therefore, considering this previous evidence and the fact that in the present study the microinjection of substance $\mathrm{P}$ produced a significant increase in MAP and HR, although the blockade of NK-1 receptors produced no effect on the chemoreflex, we may suggest that neurokinin receptors are present in the NTS and in some specific physiological situations like stress or defense reaction they can be activated to produce neuromodulation of the autonomic components of cardiovascular regulation, probably by facilitating the sympathetic out- flow, considering that in the present study substance $P$ microinjection produced a small but consistent increase in MAP and in some cases tachycardia.

With respect to the neurotransmission of the sympatho-excitatory component of the chemoreflex in the NTS, the present study indicates that substance $\mathrm{P}$ plays no major role in this processing and our previous study (15) demonstrated that excitatory amino acids are not the sole system involved in this neurotransmission. Therefore, considering that substance $\mathrm{P}$ also plays no major role in this neurotransmission, further experiments are necessary to evaluate other potential neurotransmitters that may be involved in this processing. In this case, adenosine and purinergic receptors seem to be an important system to be evaluated in the neurotransmission of the sympatho-excitatory component of the chemoreflex in the NTS of unanesthetized animals, especially due to the evidence reported by St. Lambert et al. (31) indicating that adenosine plays an important role in the neurotransmission of hypothalamic projections to the NTS.

In conclusion, these results demonstrate that microinjection of substance $\mathrm{P}$ into the lateral commissural NTS produced an increase in MAP and HR, suggesting that this neurokinin may play some neuromodulatory role at the NTS level in some specific physiological situations. However, the blockade of NK-1 receptors with WIN had no effect on the cardiovascular responses to chemoreflex activation, indicating that substance $P$ and NK-1 receptors are not involved in the neurotransmission of the chemoreflex at the level of the lateral commissural NTS.

\section{Acknowledgments}

The authors thank Rubens F. de Melo for histological technical assistance. 


\section{References}

1. Chianca-J r DA \& Machado BH (1996). Microinjection of NMDA antagonist into the NTS of conscious rats blocks the BezoldJ arisch reflex. Brain Research, 718: 185188.

2. Colombari E, Bonagamba LGH \& Machado BH (1994). Mechanisms of pressor and bradycardic responses to L-glutamate microinjected into the NTS of conscious rats. American J ournal of Physiology, 266 (Regulatory, Integrative and Comparative Physiology, 35): R730-R738.

3. Colombari E, Bonagamba LGH \& Machado BH (1997). NMDA receptor antagonist blocks bradycardic but not pressor response to L-glutamate microinjected into the NTS of unanesthetized rats. Brain Research, 749: 209-213.

4. Haibara AS, Colombari E, Chianca-J r DA, Bonagamba LGH \& Machado BH (1995). NMDA receptors in NTS are involved in bradycardic but not in pressor response of chemoreflex. American J ournal of Physiology, 269 (Heart and Circulatory Physiology, 38): H1421-H1427.

5. Machado BH \& Bonagamba LGH (1992). Microinjection of L-glutamate into the nucleus tractus solitarii increases arterial pressure in conscious rats. Brain Research, 576: 131-138.

6. Machado BH, Mauad H, Chianca-J r DA, Haibara AS \& Colombari E (1997). Autonomic processing of the cardiovascular reflexes in the nucleus tractus solitarii. Brazilian J ournal of Medical and Biological Research, 30: 533-543.

7. Brew S, de Casto D, Housley GD \& Sinclair J D (1990). The role of glutamate in neurotransmission of the hypoxic input to respiration through the nucleus tractus solitarius. In: Acker $\mathrm{H}$, Trzebski A \& O'Regan D (Editors), Chemoreceptors and Chemoreceptor Reflexes. Plenum Press, New York, 331-338.

8. Gordon FJ \& Talman WT (1992). Role of excitatory amino acids and their receptors in bulbospinal control of cardiovascular function. In: Kunos G \& Ciriello J (Editors), Central Neural Mechanisms in Cardiovascular Regulation. Birkhäuser, Boston, 209225.

9. Le Galloudec E, Merahi N \& Laguzzi R (1989). Cardiovascular changes induced by the local application of glutamate-related drugs in the rat nucleus tractus solitarii. Brain Research, 503: 322-325.

10. Talman WT, Perrone MH \& Reis DJ (1980). Evidence for L-glutamate as the neurotransmitter of baroreceptor afferent nerve fibers. Science, 209: 813-815.

11. Hall ME, Miley FB \& Stewart J M (1989). Cardiovascular effects of substance $P$ peptides in the nucleus of the solitary tract. Brain Research, 497: 280-290.

12. Gillis RA, Helke CJ , Hamilton BL, Norman WP \& J acobowitz DM (1980). Evidence that substance $P$ is a neurotransmitter of baro- and chemoreceptor afferents in nucleus tractus solitarius. Brain Research, 181: 476-481.

13. Lindefors $N$, Yamamoto $Y$, Pantaleo $T$, Lagercrantz $\mathrm{H}$, Brodin E \& Ungerstedt U (1986). In vivo release of substance $P$ in the nucleus tractus solitarii increases during hypoxia. Neuroscience Letters, 69: 9497.

14. Srinivasan $M$, Goiny $M$, Pantaleo $T$, Lagercrantz $H$, Brodin $E$, Runold $M$ \& Yamamoto $Y$ (1991). Enhanced in vivo release of substance $P$ in the nucleus tractus solitarii during hypoxia in the rabbit: role of peripheral input. Brain Research, 546: 211-216.

15. Haibara AS, Bonagamba LGH \& Machado BH (1999). Sympathoexcitatory neurotransmission of the chemoreflex in the NTS of awake rats. American J ournal of Physiology, 275 (Regulatory, Integrative and Comparative Physiology, 44): R69R80.

16. Zhang $\mathrm{CH}$, Bonagamba LGH \& Machado $\mathrm{BH}$ (1997). Substance $P$ and neurotransmission of the baro- and chemoreflex in the nucleus tractus solitarii of unanesthetized rats. J ournal of the Autonomic Nervous System, 65: 86 (Abstract).

17. Michelini LC \& Bonagamba LGH (1988). Baroreceptor reflex modulation by vasopressin microinjected into the nucleus tractus solitarii of conscious rats. Hypertension, 11 (Suppl I): 75-79.

18. Paxinos $G \&$ Watson $C$ (1996). The Rat Brain in Stereotaxic Coordinates. Academic Press, New York, NY.

19. Franchini KG \& Krieger EM (1993). Cardiovascular responses of conscious rats to carotid body chemoreceptor stimulation by intravenous KCN. J ournal of the Autonomic Nervous System, 42: 63-70.

20. Guard S \& Watson SP (1991). Tachykinin receptor types: Classification and membrane signalling mechanisms. Neurochemistry International, 18: 149-165.

21. Gallagher PJ, Paxinos G\& White SW (1985). The role of substance $P$ in arterial chemoreflex control of ventilation. J our- nal of the Autonomic Nervous System, 12: 195-210.

22. Haeusler B \& Osterwalder R (1980). Evidence suggesting a transmitter or neuromodulatory role for substance $\mathrm{P}$ at the first synapse of the baroreceptor reflex. Naunyn-Schmiedeberg's Archives of Pharmacology, 314: 111-121.

23. Kubo T\& Kihara M (1987). Blood pressure modulation by substance $P$ in the rat nucleus solitarius. Brain Research, 413: 379-383.

24. Morilak DA, Morris $M \&$ Chalmers J (1988). Release of substance $P$ in the nucleus tractus solitarius measured by in vivo microdialysis: response to stimulation of the aortic depressor nerves in rabbit. Neuroscience Letters, 94: 131-137.

25. Nagashima A, Takano $Y$, Tateishi $K$, Matsuoka Y, Hamaoka T \& Kamiya H (1989). Cardiovascular roles of tachykinin peptides in the nucleus tractus solitarii of rats. Brain Research, 487: 392-396.

26. Spencer SE \& Talman WT (1986). Central modulation of gastric pressure by substance P: A comparison with glutamate and acetylcholine. Brain Research, 385: 371-374.

27. Talman WT \& Reis DJ (1981). Baroreflex actions of substance $P$ microinjected into the nucleus tractus solitarii in rat: A consequence of local distortion. Brain Research, 220: 402-407.

28. Bond SM, Cervero F \& McQueen DS (1982). Influence of neonatally administered capsaicin on baroreceptor and chemoreceptor reflexes in the adult rat. British J ournal of Pharmacology, 77: 517524.

29. Feldman PD (1995). Neurokinin-1 receptor mediation of the vasodepressor effects of substance $P$ in the nucleus of the tractus solitarius. J ournal of Pharmacology and Experimental Therapeutics, 273: 617-623.

30. Culman J, Klee S, Ohlendorf C \& Unger T (1997). Effect of tachykinin receptor inhibition in the brain on cardiovascular and behavioral responses to stress. J ournal of Pharmacology and Experimental Therapeutics, 280: 238-246.

31. St Lambert J H, Dashwood MR \& Spyer KM (1996). Role of brainstem adenosine A1 receptors in the cardiovascular response to hypothalamic defense area stimulation in the anaesthetized rat. British J ournal of Pharmacology, 117: 277282. 